\title{
Measuring the Contribution of Construction to the Slow Recovery
}

\author{
Carlos Garriga, Research Officer and Economist
}

A ccording to the Federal Open Market Committee (FOMC), economic activity and employment in moderate rate. ${ }^{1}$ However, the main macroeconomic indicators have yet to return to pre-Great Recession trends. The slow recovery has kept the economy from growing at its historical average of 2.3 to 2.5 percent (real gross domestic product growth) and attaining 5.2 to 6 percent unemployment. ${ }^{2}$ At the existing rate of recovery and with no additional shocks, the FOMC's long-term projections predict that the economy will converge to the historical averages around 2015. Several reasons explain why the Great Recession could be different from previous recessions: deleveraging of household balance sheets, financial crises, and the global nature of the recession. This essay discusses the primary findings in a recent working paper by Boldrin et al. (2013), who argue that the construction sector is an important factor in the slow recovery of the U.S. economy. ${ }^{3}$

There has been little activity in the construction sector over the past 5 years: The number of housing starts per quarter has dropped from 400,000 single-family units during the housing boom to an average of only 100,000 units. In addition, at the peak of the housing boom, construction and related activities employed nearly 8 million workers (nearly 10 million if the real estate and leasing sector is included); this represented 5 percent of all the "value added" generated by the economy. The Great Recession took a huge toll on this sector. Nearly 1.7 million workers lost their jobs (2.5 million if real estate and leasing is included), accounting for 27 percent of workers who lost their jobs. The impact on economic activity was also sizable, accounting for 22 percent of the total decline.

Despite the magnitude of the decline in the construction sector, its contribution to the overall decline in output and employment may be even larger. The previously reported figures do not take into account that the construction sector is largely interconnected with other sectors in the economy. The production of homes and commercial structures requires purchases of intermediate goods and services from multiple sectors. These purchases include not only construction materials (e.g., wood, steel, and electrical equipment) and furniture, but also credit intermediation (e.g., mortgage financing and legal services), to name just a few. Inclusion of these other sectors implies that a decline in the demand for housing affects not only the construction sector, but all sectors that sell goods to the housing sector. The effect is propagated even further because these sectors are connected to additional sectors.

\section{Recovery of the construction sector seems a necessary ingredient for a strong and sustained recovery of economic activity and a reduction in the unemployment rate.}

The additional impact of the economic interconnections can be estimated using the input-output tables from the Bureau of Economic Analysis (BEA). ${ }^{4}$ The estimates suggest that when the additional impact of interconnections is considered, construction could account for about 35 percent of the total decline in gross output and about 52 percent of the total decline in employment. These estimates are in contrast to those of the direct impact (subtracting the construction numbers directly from the total): 22 percent of gross output and 27 percent of the decline in employment. The difference between these estimates can be attributed to the magnifying role of the sectorial interconnections.

Construction not only has been important during the recession but also is still potentially dragging down the overall economy. The contribution of the construction sector to the slow recovery can also be estimated using the BEA input-output tables with a scenario in which the construction sector continued to grow at the pre-recession 


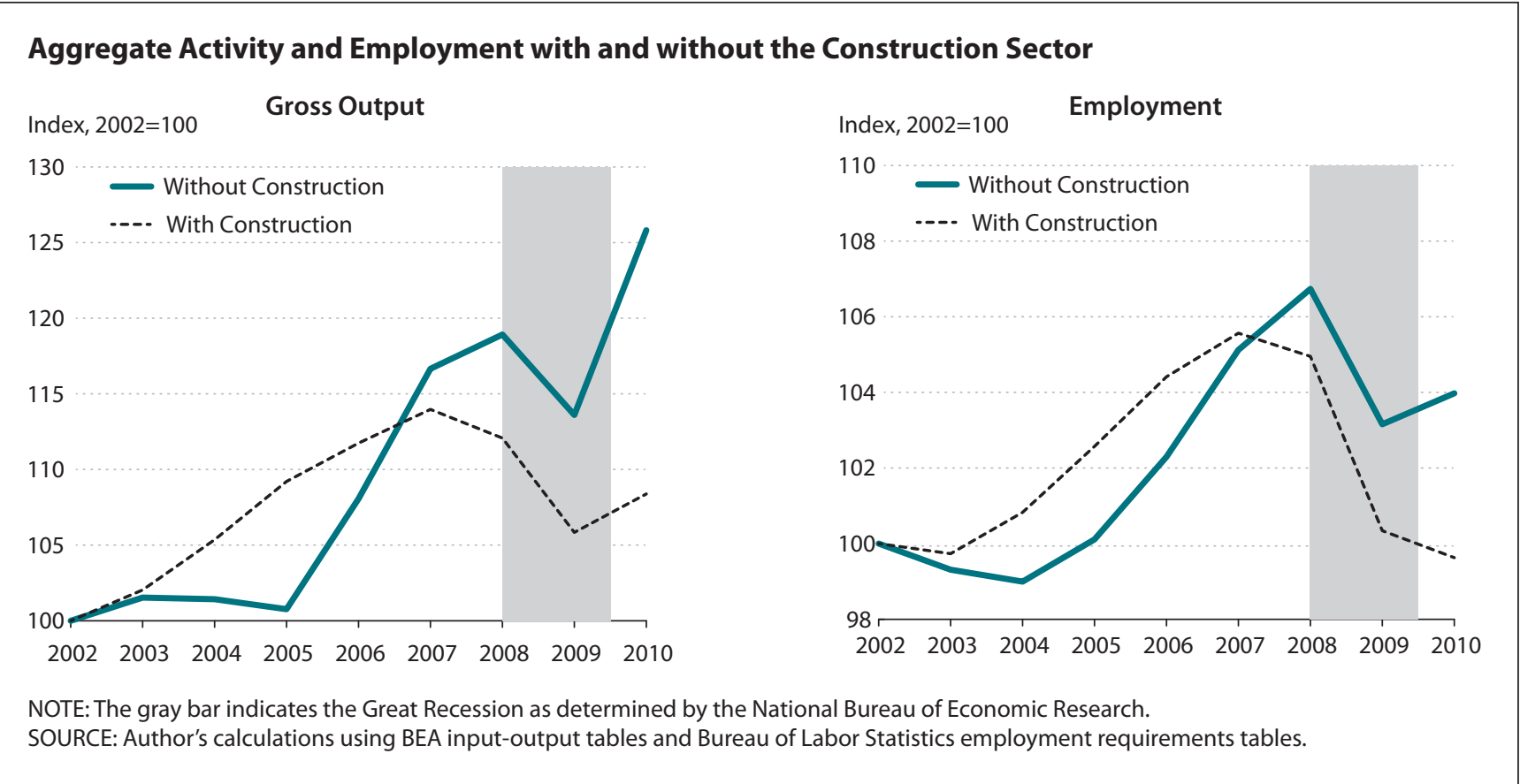

\section{Construction and the Great Recession}

\begin{tabular}{lcc} 
Period & $\begin{array}{c}\text { Change in } \\
\text { employment rate (\%) }\end{array}$ & GDP (\%) \\
\hline $\begin{array}{l}\text { 2006-09 } \\
\text { Data }\end{array}$ & -1.2 & -1.5 \\
Model simulation: & -2.3 & $-2.2^{*}$ \\
BEA input-output tables & & \\
$2009-10$ & & 2.4 \\
Data & 0.7 & 5.0 \\
Model simulation: & -0.12 & \\
BEA input-output tables & \\
NOTE: GDP, gross domestic product. *Gross output instead of \\
GDP.
\end{tabular}

levels of 2004 instead of the observed levels. The differences between the counterfactual exercise and the actual data are summarized in the table. The simulations suggest that if the construction sector were growing at the prerecession levels, total gross output should have increased by 5 percent instead of 2.4 percent as observed between 2009 and 2010. The employment level still would have decreased, but at the lower rate of 0.12 percent instead of 0.7 percent as observed in the data.

Recovery of the construction sector seems a necessary ingredient for a strong and sustained recovery of economic activity and a reduction in the unemployment rate. A clear example of construction's importance is the 2001-02 recession, when construction seemed unaffected by the general downturn and the overall recession was very short and mild. A simple way to evaluate the asymmetric role of construction in the past two recessions is to use the BEA input-output tables together with aggregate data. This approach allows removal of the construction sector from the economy to take into account both the direct and indirect effects on other industries when this sector is removed. The economy without the construction sector has lower levels of economic activity and employment, but the interesting analysis considers the relative performance of the normalized series from 2002 to 2010 . The charts summarize the paths of gross output and employment.

The charts illustrate the impact of the strong performance of the construction sector on the rate of employment growth and economic activity (the gross output simulation includes real estate and leasing services). The construction sector was an essential driver in the recovery following the 2001-02 recession. The charts also show how the weak recovery of the construction sector has affected the rest of the economy. In the economy without the construction sector (the blue line on the charts), gross output declines for only one year and recovers very rapidly. In the economy with the construction sector (the dashed black line), gross output starts to decline early but had not yet recovered from the Great Recession by 2010 (the output level in 2010 is below the 2007 level). The effects on employment growth 
are similar; the weak recovery of construction forces the employment rate to very low levels. However, both simulations highlight that, despite some recovery in employment, the overall level is lower than during the housing boom.

The simulations clearly illustrate the contribution of the construction sector to the slow recovery. The Federal Reserve's concern for housing markets and mortgage rates is well grounded in this evidence. At this point, the long-run contribution of the housing sector to the growth of gross output and employment is still unclear. It could certainly be lower than in recent history; and if so, this should be an important point in evaluating the recovery of the U.S. economy.

\section{Notes}

1 See the January 30, 2013, press release at www.federalreserve.gov/newsevents/press/monetary/20130130a.htm.

2 See "Economic Projections of Federal Reserve Board Members and Federal Reserve Bank Presidents, December 2012.” December 12, 2012; www.federalreserve.gov/monetarypolicy/files/fomcprojtabl20121212.pdf.

3 Boldrin, Michele; Garriga, Carlos; Peralta-Alva, Adrian and Sánchez, Juan. "Reconstructing the Great Recession." Working paper, Federal Reserve Bank of St. Louis, January 2013.

${ }^{4}$ More details of the analysis can be found in Boldrin et al. (2013). 